\title{
Looking to the future of land evaluation and farm planning
}

\author{
E.J. DOMINATI ${ }^{1}$, A.D. MACKAY ${ }^{1}$, J.M. RENDEL ${ }^{2}$ and P.N. SMALE ${ }^{2}$ \\ ${ }^{1}$ AgResearch, Private Bag 11008, Palmerston North, New Zealand \\ ${ }^{2}$ AgResearch, Private Bag 50034, Mosgiel, New Zealand \\ estelle.dominati@agresearch.co.nz
}

\begin{abstract}
Land evaluation has a long history of describing and quantifying the sustainable productive capacity of land. There is a global recognition of the need for this discipline to start recognising the services beyond food production provided by landscapes, as well as the impacts land uses have on receiving environments. An ecosystems approach was used to extend land evaluation to include additional outcomes and was paired with farm system optimisation to explore farm system design. The approach was tested on a sheep and beef farm to explore the added benefits of steep land retirement for flood mitigation and soil conservation and potential trade-offs with farm productivity. The approach showed successfully that it is possible to aim for multiple benefits ranging from increased profit to decreased environmental footprints. Such capability to define and include ecological boundaries within which resources should be managed is a feature that analytical farm system frameworks will require into the future.
\end{abstract}

Keywords: multi-functional land evaluation, ecosystem services, farm system, optimisation

\section{Introduction}

Land evaluation is formally defined as 'the assessment of land performance when used for a specified purpose'(FAO 2007) and has a long history of describing and quantifying the productive capacity of land. Historically, the land evaluation procedure uses physical limiting factors arising from climate, hydrology, landforms and soils as the basis for assessment of sustainable yields with critical values determining suitability boundaries.

Two new trends emerging from land evaluation frameworks globally (FAO 2007) are the recognition of the services beyond food production provided by landscapes and the need to include as part of any analysis the impact a land use has on receiving environments.

The "ecosystems approach" is a rapidly emerging discipline to assess the benefits beyond food production from natural resources including land. This approach is based on the concepts of natural capital (stocks of natural assets) and ecosystem services. Ecosystem services are defined as 'the flows of benefits people obtain from ecosystems' (MEA 2005), such as food, flood mitigation, nutrients filtration, greenhouse gas regulation, waste recycling, pest regulation, a safe place to build and live, vistas and for many their spiritual home (Dominati et al. 2010).

Adding an ecosystem services element to land evaluation enables the supply of all the benefits obtainable from land to be linked to the performance of a combination of land type, enterprise (use) and practices (management) (Figure 1). This provides a more complete assessment of the use of natural resources, assists in defining natural ecosystem boundaries and provides better information on progress towards not only economic, but also the environmental, social and cultural outcomes desired by land owners and community of interests (Dominati et al. 2016).

Because farms sit on landscapes within catchments, decisions on-farm impact beyond the farm boundary. The challenges currently faced in New Zealand with 
water quality demonstrate that soils have a finite capacity to retain nutrients and receiving environments have a finite capacity to assimilate nutrients. Therefore, both ecological boundaries and impacts of production on air, land and water quality must be included in land evaluation frameworks and farm systems analysis and design into the future. Farms are an assemblage of multiple landscapes that include a mix of topographies, range of soil types with different strengths and weaknesses, all of which influence pasture and crop production as well as the provision of all other ecosystem services under a use. Importantly, these land units show different responses to inputs and management practices. Quantitative information on land capability, current condition and trends (Figure 1) are key to the farm system design process.

In New Zealand, land use capability classification (Lynn et al. 2009) has been the basis for assessing land capability and therefore potential suitability for sustained production taking into account the physical limitations the land may have. Additional information on the current condition of the farm resources (soil, waterways, native remnants...) needs to be paired with information on built infrastructure, as well as land management strategies, resulting from current practices and knowledge built over the years. In this paper, an ecosystems approach (Dominati et al. 2010) was used to inform land evaluation and was paired with a new generation farm system optimisation capability to explore the implications and utility of adding additional services and operational boundaries on farm systems design and performance.

Table 1 Description of land management units.

\section{Methods}

\section{New farm optimisation capability}

To deliver multiple outcomes the farm system needs to be designed to fit land capability which requires new analytical capability from farm scale models. The new Integrated Farm Optimisation and Resource Allocation Model (INFORM) (Rendel et al. 2013; Rendel et al. 2015) was used in this study. It has the ability to integrate independently obtained biological data from each of the land management units (similar natural resources and management practices) within the farm system and place operational boundaries on the use or emissions from each land management unit before optimising profit. The optimisation routine within the model uses the information from each land management unit to identify the mix of production enterprises and management regimes that maximise profit (EBITDA) for the business. This represents a step change over a standard approach that typically explores economic outcome first and then mitigates for specific losses (e.g. Nitrates $\left(\mathrm{NO}_{3}^{-}\right)$, Phosphorus (P), Greenhouse Gases (GHGs)) and conditions. Optimisation of the farm system within operational boundaries considers the consequences of multiple drivers simultaneously as an integral part of the farm system design and analysis.

\section{Study site}

To explore the implications and utility of adding additional services and operational boundaries on farm systems design and performance the approach was tested on a sheep and beef farm situated near Whanganui. It is a 1125 ha summer-moist hill country farm running 6520 stock units mostly as a high performance sheep flock (80:20 sheep:cattle) across an effective pastoral area

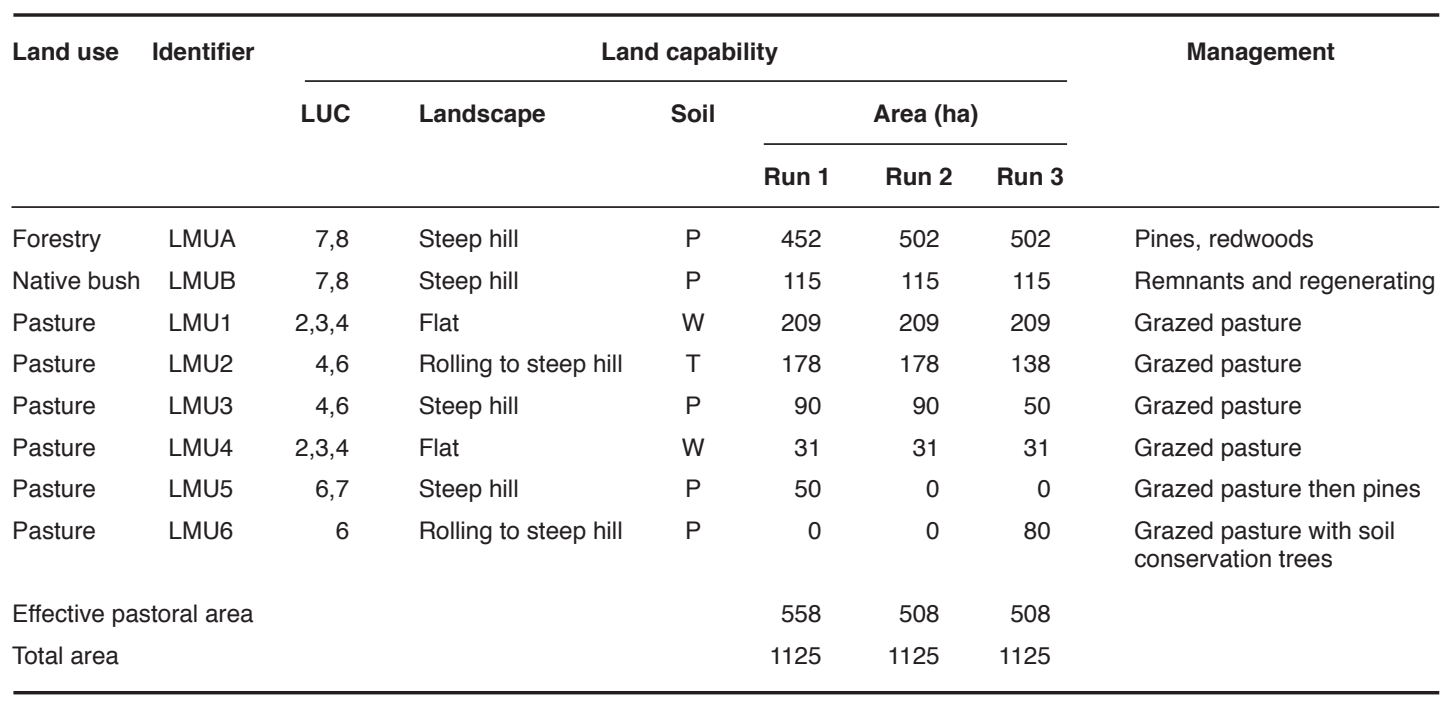


of 558 ha (11.7 SU/ha). Approximately $80 \%$ is hill and steep land formed from weakly consolidated sandstone, the remainder being undulating to rolling down-lands formed from volcanic loess and alluvial flats. The farm is divided into a numbers of land management units (LMUs) (Table 1). These units were set up using the property's whole farm plan, which included information on the soils and land use capability (LUC), strengths and weaknesses of different part of the farm, reflection on current and future potential uses of each land unit, risks of soil erosion or compaction based on land capability, connectivity between different parts of the farm, and the need to protect receiving environments over time.

\section{Farm system analysis}

The impacts of steep land retirement for flood mitigation and soil conservation and the trade-offs this can represent with the farm productivity were explored in two scenarios. In addition to the current (non-optimised) farm system (Run 1), the two scenarios modelled were: An optimised scenario (Run 2) where 50 ha of steep hill (LMU5) was converted from pasture to forestry, and a soil conservation scenario (Run 3), where 80 ha from LMUs 2 and 3 were planted in soil conservation poplar trees at $100 \mathrm{stems} / \mathrm{ha}$ on Class 6 land to create a $6^{\text {th }}$ LMU (LMU6) (Table 1). Impacts to the farm system, grazing regime, profit and environmental outcomes were assessed for all three runs.

The range of ecosystem services provided by soil conservation trees beyond erosion prevention, included flood mitigation, potential forage source, carbon storage and shade and shelter (Dominati et al. 2014), as well as their location in the farm landscape, were carefully considered at the farm planning stage to get multiple beneficial impacts from the investment. For the soil conservation scenario, it was assumed that the death rate for sheep and R1 beef was reduced from $5 \%$ to $4.5 \%$ and weaning percentages were increased by $1 \%$ to simulate the effect of shelter and the shade provided from the trees to the animals (Dominati et al. 2014). Pasture production under spaced trees was also assumed to be $10 \%$ lower than without trees. The costs of maintaining soil conservation tress (pruning, pollarding) were added to LMU6 costs.

All three scenarios were modelled as established stable systems. As INFORM does not output environmental footprints of optimised farm systems, the OVERSEER ${ }^{\circledR}$ nutrient budget was used, based on the optimal systems generated by INFORM, to model N, P and GHGs losses from the three scenarios. Results are presented in Figures 2 and 3.

\section{Results}

The optimisation of the farm system using the INFORM model resulted in a major change in the farm's livestock

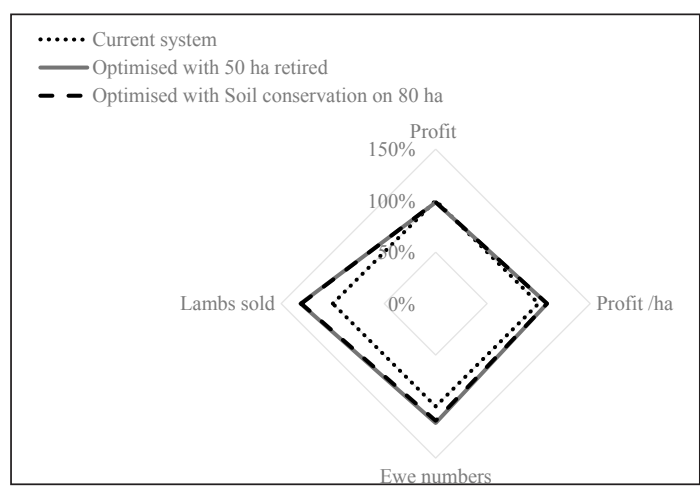

Figure 2 Farm system information for the 3 scenarios modelled with INFORM. All indicators in \% different from current situation (Run 1).

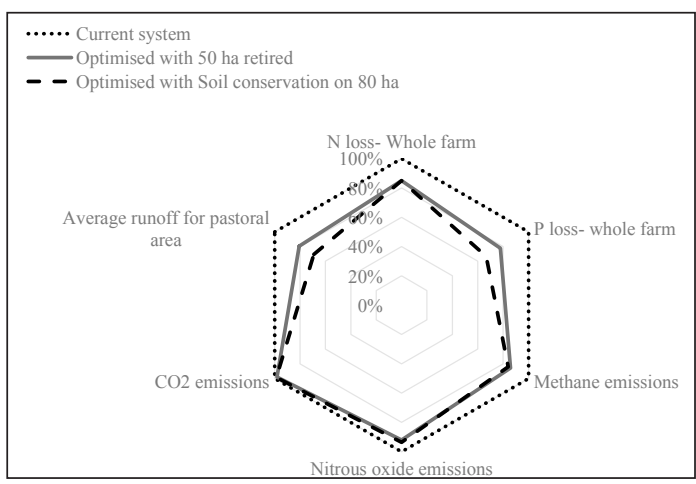

Figure 3 Environmental footprint for the 3 scenarios modelled with OVERSEER. All indicators in \% different from current situation (Run 1).

policy, shifting from 80:20 sheep:cattle to a sheep only system. The number of SU/ha did not change much going from 11.7 SU/ha for Run 1, to $11.6 \mathrm{SU} /$ ha for Run 2, and 11.3 SU/ha for Run 3. Despite retiring 50 ha of marginal pastoral land into forestry (Run 2) and planting 80 ha of wide-spaced trees (Run 3) overall profit from the pastoral part of the farm was maintained (Figure 2) while profit/ha of the reduced pastoral base increased by $8 \%$ (Figure 2). Ewe numbers and lambs sold increased by $15 \%$ and $31 \%$, respectively, through improved grazing management (Figure 2). The planting of 50 ha of steep land to forestry and spaced planted poplar trees on 80 ha of LMU 2 and 3, decreased runoff and thereby greatly improved flood mitigation by $19 \%$ and $31 \%$ respectively for Runs 2 and 3 (Figure 3).

The planting of 50 ha of forestry (Run 2) and subsequent changes in the livestock policy reduced nitrogen $(\mathrm{N})$ and $\mathrm{P}$ losses from the whole farm by $15 \%$ and $22 \%$, respectively, from the current system (Figure 3). The implementation of spaced planting of soil conservation trees (Run 3) showed no further reduction in overall $\mathrm{N}$ loss (Figure 3 ) but an additional 
$11 \%$ decrease in P loss for the whole farm, compared to the current. Pairing the forestry enterprise with spaced planted and soil conservation trees reduced GHGs emissions, as well as runoff for the whole farm.

\section{Discussion}

The use of an ecosystems approach based on multifunctional land evaluation, paired with farm optimisation modelling showed successfully that it is possible to explore and integrate multiple benefits ranging from increased profit to decreased environmental footprints, into the farm system. The approach was able to identify a farm system which made an enterprise change to forestry as well as invested in space planted poplar trees, primarily to protect the soil resource and pastoral base that balanced the impacts on the farm's productivity, profitability and receiving environments. Such capability will be required increasingly into the future as ecological boundaries become part of the farm operating environment.

One of the challenges and limitations of the method is the amount of information required on both the natural resources and the farm system. The information for the farm studied came from a 'whole farm plan' from the Sustainable Land Use Initiative (SLUI) of Horizons Regional Council as well as consultation with the farmer for production and financial information. SLUI plans or Level 2 and 3 farm plans from the Land and Environment Planning Toolkit of Beef + Lamb New Zealand (http://beeflambnz.com/lep/) are good examples of current approaches to land evaluation and planning. The challenge is to define uniform land management units based on both land capability, built infrastructure and land management, and then adapt the management of each LMU to fit the overall farm system as well as ecological boundaries based on land capability (Mackay et al. 2015). Farm system optimisation at the LMU level allows the analysis to be shifted from the use of average data, but it requires more detailed information for each LMU.

The results presented here include only one option for livestock policy, but a range of farm systems with similar EBITDA could be considered depending on the farmer's preferences. It then comes down to evaluating those options against environmental boundaries and environmental impacts targets before the approach can be applied in practice.

The concept of adding ecological or operational boundaries, within which land use must operate, moves the analysis from managing a farm as an island to managing the farm within a landscape from which the community seeks multiple outcomes. Some boundaries will be defined by the landowner at the farm scale (related to sustaining the quality of natural capital stocks or to specific farm performance objectives) and some informed from wider scales (e.g. catchment thresholds on nutrient losses).

Building an ecosystem service approach into land evaluation and farm planning from the beginning also offers a method for separating out and assessing the contribution from the natural and built capital to the farm system and the delivery of the services.

Here an investment in ecological infrastructure, soil conservation trees, was tested. The financial analysis over the years for this investment is not presented, but the outputs from INFORM show how it impacts on the grazing regime, farm system and profit when the trees are established. This demonstrates to the land manager that improving economic and environmental outcomes simultaneously should be possible and presents the options to consider before actual changes are made to the farm system. The contribution of investments in built infrastructure (e.g. irrigation, feed-pads, herd homes) to the farm system and ecosystem services delivery can be quantified and valued the same way (Rendel et al. 2015).

\section{Conclusion}

This study tested the use of an ecosystems approach to inform land evaluation for multiple outcomes, paired with farm system optimisation to explore farm system design. The approach showed successfully that it is possible to aim for the delivery of multiple benefits ranging from increased profit to decreased environmental footprints when designing farm systems by optimising the use of natural capital. Such capability to define and include ecological boundaries within which resources should be managed is a feature that analytical farm system frameworks will require into the future. It also creates the capacity to assess if the farm system is sustaining natural capital stocks (soils, vegetation, could include social...) on which the future business opportunities are based.

Farm optimisation within boundaries provides a basis for conducting a more complete analysis of the tradeoffs between business performance, ecosystem services delivery and environmental outcomes. It will also be useful in reporting to the consumer and market on the environmental performance of the farm operation.

\section{ACKNOWLEDGEMENTS}

AgResearch's core funded programme Resilient Rural Communities supported this study.

\section{REFERENCES}

Dominati, E.J.; Mackay, A.D.; Lynch, B.; Heath, N.; Millner, I. 2014. An ecosystem services approach to the quantification of shallow mass movement erosion and the value of soil conservation practices. Ecosystem Services 9: 204-215. 
Dominati, E.J.; Mackay, A.D.; Bouma, J.; Green, S. 2016. An Ecosystems Approach to Quantify Soil Performance for Multiple Outcomes: The Future of Land Evaluation? Soil Science Society of America Journal 80: 438-449.

Dominati, E.J.; Patterson, M.G.; Mackay, A.D. 2010. A framework for classifying and quantifying the natural capital and ecosystem services of soils. Ecological Economics 69: 1858-1868.

FAO 2007. Land Evaluation: Towards a revised framework. In: Food and Agriculture of the United Nations, Rome. ISSN 1729-0554. pp. 124.

Lynn, I.; Manderson, A.; Page, M.; Harmsworth, G.; Eyles, G.; Douglas, G.; Mackay, A.; Newsome, P. 2009. Land Use Capability Survey Hand-book - a New Zealand handbook for the classification of land - 3rd ed. Hamilton, Agresearch, Lincoln, Landcare Research, Lower Hutt, GNS Science.
Mackay, A.D.; Dominati, E.J.; Rendel, J. 2015. Looking to the future of land evaluation and farm systems analysis. In: New Zealand Institute of Primary Industry Management. Wellington, New Zealand, NZIPIM. pp. 28-31.

MEA 2005. Millennium Ecosystem Assessment: Ecosystems and Human Well-being: Synthesis. Washington DC, Island Press.

Rendel, J.M.; Mackay, A.D.; Manderson, A.; O’Neill, K. 2013. Optimising farm resource allocation to maximise profit using a new generation integrated whole farm planning model. Proceedings of the New Zealand Grasslands Association 75: 85-90.

Rendel, J.M.; Mackay, A.D.; Smale, P. 2015: Valuing on-farm investments. Journal of New Zealand Grasslands 77: 83-88. 
